\title{
"They open the door, kick you out, and say, 'Go'" \\ Reentry Challenges After Wrongful Imprisonment
}

\author{
Amy Shlosberg \\ Fairleigh Dickinson University \\ Madison, New Jersey \\ U.S.A \\ Jordan Nowotny \\ Fairleigh Dickinson University \\ Madison, New Jersey \\ U.S.A \\ Elizabeth Panuccio \\ Fairleigh Dickinson University \\ Teaneck, New Jersey \\ U.S.A \\ Valli Rajah \\ John Jay College of Criminal Justice \\ New York, New York \\ U.S.A
}

Drawing on 24 in-depth semi-structured interviews with exonerees, this study explores the postrelease experiences and struggles upon reentry. Findings highlight the urgent need to provide support to individuals who have been victimized by the very system that is supposed to protect their fundamental rights. It is essential that more customized holistic approaches be implemented to address the wide range of often-interrelated practical, social and psychological issues. Furthermore, services should be provided immediately upon release and be offered indefinitely as hardships often linger well after release. Ultimately, the goal of this paper is to encourage action toward comprehensive support after wrongful imprisonment.
I. Introduction
II. Consequences of Incarceration and Barriers to Reentry for Exonerees
III. Data and Methods

IV. Results
A. Sample Description

A. First Day Out

B. Insufficient Support

C. Long Road Ahead

V. Discussion

A. Limitations and Future Research

VI. Conclusion 


\section{Introduction}

To date, there have been 367 DNA exonerations (Innocence Project, 2020) and over 2,600 exonerations when including non-DNA cases (National Registry of Exonerations, 2020). However, since there is no systematic method to determine the accuracy of a criminal conviction, and since the United States warehouses 2.2 million prisoners (Kaeble \& Glaze, 2016), and incarcerates 670 people per 100,000 citizens, (Walmsley, 2016), the true number of wrongful convictions is likely significantly higher. In many cases the actual guilt of the convicted individual is known only by that individual, therefore making the true number both unattainable and unknowable (Gross \& O’Brien, 2008).

In this research, we examine the struggles faced by wrongfully convicted individuals after they return to the community. Scholars have devoted a great deal of attention to research on factors that contribute to wrongful convictions- such as eyewitness mistakes, false confessions and "junk" science (Garrett \& Neufeld, 2009; Kassin, 2002, 1997; Wells, et.al, 1998). In addition, many have shared their stories of innocence through biographical and autobiographical books (Leo, 2005). Most of these accounts, however, focus on life leading up to the arrest and the legal issues resulting in their wrongful conviction (Leo, 2005). While important, these accounts tell us little about what happens after release. The impact of the wrongful conviction includes more than just a struggle to survive prison while fighting for one's freedom (Westervelt \& Cook, 2012); the effects linger well after success is won in the courtroom.

Justice for those who have been exonerated extends beyond just freedom from confinement; the damage inflicted by the criminal justice system through wrongful conviction destroys lives and requires long-term, sustained restoration and support long after release. To achieve this there must first be an understanding as to what exonerees need to rejoin society and prosper and how those needs shift over time. In this study, our goal is to contribute to the research on wrongful convictions and prompt action toward comprehensive and individualized support for returning exonerees.

\section{Consequences of Incarceration and Barriers to Reentry for Exonerees}

Researchers have generally found that wrongfully convicted individuals suffer from many of the same consequences as other formerly incarcerated people upon release from prison, such as psychological trauma, long-term mental health challenges, and stigmatization. In addition to these, however, scholarship has shown that the lived experiences of wrongful imprisonment might be worse than for other incarcerated people due to the unjust nature of the situation (Campbell \& Denov, 2004). For this population the transition after incarceration is often compounded by a host of unique experiences (Westervelt \& Cook, 2008), such as the suddenness of release without time to prepare (Grounds, 2004), mistrust and fear by community members that are either unfamiliar with what exoneration means or doubt the person's authentic innocence (Campbell \& Denov, 2004), and absence (or denial) of post-release programming, support or housing (Weisman, 2004; Westervelt \& Cook, 2010). 
Evidence suggests that formerly incarcerated individuals report substantial postincarceration mental health challenges, such as depression, posttraumatic stress disorder (PTSD), and anxiety (Mallik-Kane \& Visher, 2008; Bronson \& Berzofsky, 2017; Alexander Bloch at al., 2020). These challenges are largely produced by the prison environment itself. Under the strict formal and informal rules of the prison, individuals often experience the frustration and deprivation of living in a total institution (Goffman, 1961; Sykes, 1958) that promotes self-destructive changes in behavior (Haney, 2002; Zamble \& Porporino, 2013; Middlemass \& Smiley, 2020) and unhealthy coping mechanisms (Branham, 1992; Clemmer 1940). These issues often lead to problems after release including increased substance abuse (Petersilia 2003, James \& Glaze, 2006; Chandler \& Fletcher, 2009; Chamberlain, et.al., 2019) and diminished long-term psychological health (Zamble \& Porporino 1988; Gonzalez \& Connell, 2014; Wilper, et al., 2009).

Some researchers have studied the mental health of exonerees specifically and found that these individuals experience similar psychological, emotional, and social challenges as parolees (Campbell \& Denov, 2004; Grounds, 2004; Cook et.al., 2014; Westervelt \& Cook, 2010; Wildeman et al., 2011). In many cases, the nature of the wrongful detention may exacerbate these effects. Simon (1993) found that even brief wrongful detention (less than 24 hours) may result in long-term psychological trauma. However, since wrongly convicted individuals serve 11 years on average (Gross \& Shaffer, 2012), these damages are amplified. In early work on exoneree mental health, Adrian Grounds (2004) interviewed exonerees and concluded that "those released following wrongful conviction and imprisonment may have significant psychiatric and adjustment difficulties of the kind described in other groups of people who have suffered chronic psychological trauma" (p. 175). Grounds also found that the overwhelming majority of exonerees suffered from PTSD and personality changes, while a smaller, though still substantial, subgroup experienced depression, panic disorders, and paranoia. Consequently, exonerees report difficulty sleeping, increased irritability and moodiness, and other symptoms that can make life after prison even more arduous. Likewise, Westervelt and Cook (2010) spoke with death row exonerees and found that these individuals had difficulty adapting to outside life and experienced prolonged feelings of bitterness and anger.

In addition to mental health issues, exonerees must also deal with negative perceptions by the public. It is well established that people hold negative stereotypes of formerly incarcerated offenders (Dijker \& Koomen, 2003; Hirschfield \& Piquero, 2010; Rade, et. al., 2016; Moore, et.al., 2018); exonerees are viewed similarly (Thompson, et. al., 2012; Clow \& Leach, 2015; Kuckucka, et. al., 2019; Campbell \& Denov, 2004; Keene, et. al., 2018; Menard \& Pollock, 2014). Lopez (2002) argues that "[t]he most damaging injury inflicted upon the wrongfully convicted is not necessarily the time lost behind bars, but the stigma that follows them for the rest of their lives" (Lopez, 2002, p.720). This stigma could be due in part to the public's inadequate understanding of exoneration, lack of awareness about the general prevalence of wrongful convictions and perception that exonerees are dangerous or socially undesirable (Bell, et. al., 2008; Clow \& Leach, 2009; Thompson \& Levett, 2010; Blandisi et al., 2015). Recent research has also shown that race might play a factor in how exonerees are viewed by the public (Howard, 2018). Finally, some cases receive substantial negative publicity making it more likely that the individuals involved face higher scrutiny than others that escape similar attention (Martin, 2006). Unsurprisingly in light of these studies, exonerees feel they are not accepted by community members, that their 
innocence is doubted, and that they have to continue to fight to assert their innocence and reconstruct their reputations to earn the public's trust (Westervelt \& Cook, 2010).

Employment can sometimes mitigate the barriers of reentry by helping returning citizens obtain economic security, medical care, housing, and other positive outcomes (Haney, 2002; Grounds \& Jamieson, 2003). Finding and maintaining employment, however, is often difficult for individuals reentering society (Pager, 2003; 2008; Grounds \& Jamieson, 2003; Berg \& Huebner, 2011; Looney \& Turner, 2018) and exonerees cite it as their most important concern (Westervelt $\&$ Cook, 2010). For many exonerees, the stigma associated with their status reduces likelihood of finding meaningful work and they may face hiring discrimination similar to ex-offenders (Kuckuka et al., 2019). Like parolees and other formerly incarcerated people, exonerees are subject to background checks that often turn up criminal records even after expungement (Shlosberg et al., 2012) and remain visible to potential employers (Chunias \& Aufgang, 2008). Even when criminal records are not uncovered, exonerated people are required to explain their employment gap (Armbrust, 2004).

While these issues are not uncommon for other formerly incarcerated individuals (nonexonerees), it may be more difficult since exonerees are often ineligible for job training, vocational services, and opportunities that are often made available to parolees (Scheck, et.al., 2000; Grounds, 2004; Cook, Westervelt, \& Maruna, 2014). Altogether, the lack of training, long gaps in employment history, and negative public perception make it extremely difficult for these individuals to find and retain jobs. Consequently, without resources from work, many exonerees become dependent on others, potentially straining supports in the community (Scott, 2010).

With the challenges of gaining meaningful employment and the lack of assistance or guidance throughout the reentry process, exonerees are likely to seek compensation to achieve basic security and help restore their lives (Martin, 2006). Financial compensation can aid exonerees in several ways. Not only does payment help exonerees overcome the substantial barriers to re-entry, it may make them feel valued by society (Mandery, et. al, 2013). However, compensation is not enough. Westervelt and Cook (2012, p. 237) state, "[t]he overarching element they wish for is restoration, restoration of the components of their financial, familial and emotional lives that they believe were destroyed by their wrongful conviction." Related to financial security, many exonerees also lack adequate housing and although some exonerees have family or friends to stay with, at least in the short term, many live temporarily with their lawyer (Westervelt \& Cook, 2008) or resort to living in an unsafe temporary housing condition, such as homeless shelters (Chunias \& Aufgang, 2008).

The harms of being wrongfully convicted continue long after an individual is exonerated. Westervelt and Cook (2008) describe the imprisonment of an innocent person as a "sustained catastrophe" that extends over long periods, much like the experience by abuse victims or prisoners of war. Following release, these individuals struggle with seemingly simple everyday tasks like relearning how to sleep, eat, shop, walk, use money, and even dress themselves (Westervelt \& Cook, 2012).

In this paper we aim to expand on the work cited above to describe and explore the challenges exonerees face after prison. Although there are also many exoneree success stories, 
here we highlight issues and problems that exonerees face at different time periods after release. Our hope is that by concentrating on these specific narratives we might better direct local and national support to improve post-prison life for exonerees.

\section{Data and Methods}

We conducted semi-structured, in-depth interviews with a sample of 24 exonerees over the course of approximately five years (November 2015 - June 2020). For the interview protocol, we follow Rubin and Rubin's (2005) suggestions for initial broad qualitative questions to provide conversational discussions with the intention to investigate deeper or "thicker" descriptions of meaning (Geertz, 1994). This data collection approach is suitable for this type of research given that the goal is to uncover and unpack the individual lived experiences of respondents (Charmaz, 1990).

We initially recruited exonerees to participate by reaching out to our professional contacts who work closely with this population. Following interviews individuals recommended others that they thought would be interested in speaking with us. Once exoneree contact information was obtained, a member of the research team reached-out to the individual, explained the purpose of the study and provided a consent form. If respondents agreed to the interview, the research member scheduled, and later interviewed, individuals in-person or virtually. Participants were compensated $\$ 100$ for their time. Individuals were included in the study if they were wrongfully convicted of a crime and later cleared of all charges.

In the interview we asked a series of questions related to individual incarceration and postincarceration experiences. For insight into life after prison, we asked about obstacles that individuals faced upon release (such as health issues, financial struggles, personal relationships, fears, etc.) and feelings of preparedness for community reentry. We also asked exonerees about successes and challenges associated with employment, relationships, health, the legal system and individual coping strategies. We inquired about the process and/or struggles with reintegration and the idea of closure, attitudes toward law enforcement and the criminal justice system. Finally, we asked respondents to share their own ideas on how reentry could be improved for other exonerees.

All interviews were audio-recorded, transcribed verbatim and assigned a confidential code number (e.g., R1, R2, R3, etc.). Coding and analysis were conducted in four steps. In step one, a sub-group of interviews were reviewed to compile a close code outline - a list of concepts and themes represented in the data. In step two, all interviews were coded line by line, where sections of text were assigned descriptive labels (assigned open-codes). Once open coding was complete, in step three, data were integrated by grouping open coded segments under the close code outline. Lastly, data was analyzed by comparing and contrasting the material grouped together to identify patterns, dimensions and relationships among the identified concepts and themes.

\section{A. Sample Description}

Twenty-four individuals were interviewed for this study; each had been wrongfully convicted and incarcerated between five and 28 years with an average of 18.5 years. The majority of the participants are male $(\mathrm{n}=17,70.8 \%$, ) with seven $(29.2 \%)$ female participants. Ten $(41.7 \%)$ 
participants are White, nine (37.5\%) are African-American or Black and five (20.8\%) are Hispanic or Latinx. ${ }^{1}$ Three respondents were sentenced to death and five were sentenced to life without the possibility of parole. The remaining sentences ranged from seven to 65 years. The majority of participants were wrongfully convicted of murder $(n=15,62.5 \%)$. Other charges of wrongful conviction included sexual assault, robbery, aggravated assault, child sexual assault and kidnapping. Finally, individuals were drawn from all U.S. regions: 10 were from the Northeast, two from the Midwest, nine from the South, and three from the West. ${ }^{2}$

As noted in Dworkin (2012), sample sizes for qualitative work tend to be smaller than samples in quantitative studies. Our intention was not to speak for all exonerated people (though we are confident that the experiences narratives provided here speak for at least some), but to closely examine how reentry is experienced and described by exonerees, how these experiences change over time, and why so many barriers exist.

In the findings section below, when possible, we try to use specific quotes to illustrate key concepts throughout the paper. In some cases, we paraphrase or trim what individuals told us to flow within the paper and/or to obscure information that might identify respondents. This was especially important since the known universe of exonerees is small and we wanted to protect the identities of all those that volunteered their stories. Although some individuals were quoted more than others, all voices were equally important.

Finally, throughout the paper although we use the term 'exonerees' to collectively discuss the respondents, some of the quotes and analysis describe time periods prior to legal exoneration. We use this collective term to avoid confusion while still focusing on the reentry experiences of all those interviewed.

\section{Results}

The personal costs of wrongful conviction are vast. Acute and chronic harms are caused at all stages of the criminal justice process - arrest, legal proceedings, conviction, and prison. When individuals are released, our society expects that freedom is good enough and that they'll be successful on their own, with little or no state support. For most, however, the euphoria of release, however blissful, is fleeting and followed by substantial challenges. From those we spoke with, the challenges often began on day one and continue throughout their lives.

In this paper we first describe the context of initial release for those we spoke with and the tribulations immediately faced in day-to-day life. In the second section we discuss the resources (or lack thereof) available to exonerees after release. Finally, in the third section we outline longterm challenges. From an extensive initial list, we group these barriers into five primary categories relating to technology, financial stability, stigma, mental health, and social relationships.

\footnotetext{
${ }^{1}$ Race/ethnicity and gender demographics were compiled from the National Registry of Exoneration. (http://www.law.umich.edu/special/exoneration/Pages/detaillist.aspx) accessed on June 25, 2020.

${ }^{2}$ Regions were created from Census categories.
} 


\section{A. First Day Out: Elation and then Paralysis}

It was surreal, I step out of the courtroom and the sky, the blue, not a cloud in sight. The sun was out, sunlight on my face and fresh air. I guess it felt surreal. Then I stepped to the press conference, there was a ton of media there, everything I ever wanted to say. [...] I spoke for like two and a half hours giving an off the cuff presentation. I went to a luncheon after that. I had some of my favorite foods. Then I went to my aunt's house and just sat around the table awkwardly which was this great big party to the break of dawn but by that point I had really lost touch with everybody. I really couldn't relate to the people that were there so I felt out of place so I just wound up going outside and just sitting outside for most of the night. [R1]

R1's quote demonstrates the range of emotions felt by many exonerees upon release. Those we spoke with often felt initial bliss; finally, they were free and finally their voices were heard. And although each celebrated in different ways - some very publicly, and some very privately the initial joy sobered considerably as reality set in. This sobering period varied by person. For individuals like R6, elation was quickly replaced by fear and apprehension as he realized an unfamiliar world lay before him: "the second day I got out, it was, I was sweating profusely, I was very, I was nervous, I was afraid. [I] Didn't know what to expect."

The majority of those we interviewed in this project were notified of their release suddenly and found themselves ejected from detention without time to plan. While perhaps well intended, as few would choose to be detained any longer, the sudden expulsion created initial hardships and few from our sample were fortunate enough to have enough saved resources to overcome these challenges. Some of our respondents, like R9, used up their entire savings in the legal processes prior to, during and after incarceration. R16 described his frustration with the state after release:

[I got] zero. I did not receive nothing in any form of any compensation or anything that would assist me, you know, upon my reentry. No type of tools whatsoever. And I can specifically say here [in my state], there is no compensation law, you know, for those who injustice fell upon their lap, and when I came home, I had no help from the mayor. I had no help from the government. I had nothing but what I went in with.

The most anyone received at release was gate money, a state-specific small monetary package set according to years served ${ }^{3}$, and whatever individuals still had in his or her commissary account. In some cases, the release was so rapid there wasn't enough time to gather personal belongings, or as R5 put it, "they open a door, kick you out and say 'go." Many we spoke with had to return to the prison to collect their things and any amount owed to them by the state. ${ }^{4}$ At most, exonerees left prison with little more than the clothes on their backs and just enough money for a train ticket. R11 told us she received $\$ 100$ from the state and wanted to frame the check to

\footnotetext{
${ }^{3}$ For our sample, the amount varied from $\$ 50$ to $\$ 100$.

${ }^{4}$ Individuals from our sample were released at different times. Some states have made important improvements to their release policies but not all.
} 
remind her of her liberation. However, when she left prison, she didn't have enough support and was forced to cash the check out of necessity. She now just has a photograph of it to remind her. Equipped with few resources and released into a changed world, many of the exonerees felt the embeddedness of prison life after release. R11 described this feeling as a form of paralysis:

I didn't know how to do anything. I was...you're kind of childlike you know? You need permission to do everything. So even to take a step in one direction or the other, you kind of look to somebody like, "is this okay?" It's strange and Instead of being a stranger in a strange land, I felt like a stranger in a familiar land you know? I spoke the language, but I wasn't sure what I was allowed to do. So, you're very unsure of yourself in every way and I couldn't make decisions.

Like R11, R24 saw himself as an outsider. His family took him out for pizza to celebrate the freedom he had won and although many of his family members were there to celebrate with him, he felt distant and unsure of himself.

[T] hat night, we took a lot of pictures and everything and I don't know why, but pizza is something that I wanted when I first came home. So, we went to go eat Pizza Hut and my mom, my parents were there, well, my mom and my stepdad because my dad passed away while I was incarcerated and, and my son, and it was our first visit together. So, it was really hard and difficult and I just, I still couldn't believe it. I didn't know how to act. I didn't know how to respond. It's like I felt foreign, you know, it was so different. It's like they're my family, but I haven't been around them in so long and even though they would come visit it was still, you know, different. I don't know if that makes sense.

Similarly, R15 felt the shock of release right away. After nearly two decades in prison, R15 was relieved that she was finally able see her son, a toddler when she was sent away and now an adult. After the reunion with her family she quickly became overwhelmed by how ill-equipped she felt living what she felt was a normal life. Fortunately, unlike many others we spoke with, she had her brother and other key support actors there to assist her. She told us that without them, she wouldn't have survived the transition.

My first day out of prison. [...] I was up most of the night. I got to watch my son sleep for the first time in [almost two decades] and woke up and see him in his bed, do normal parent stuff. But the next day I called my brother. [...] I got on the phone with him and I just started crying and I said, I don't have a toothbrush. ... I wasn't prepared for this. [...] And I said I had absolutely nothing to wear and I put back on my prison uniform, and I said, "that's all I've got is a prison uniform." And, it just hit me, what am I going to do? Where am I going to go? [...] So, my brother said, "listen to me. I buy clothes for the kid. You can fit in his clothes. You go up and get a shirt and a pair of shorts. You take a shower. Put on a clean outfit. I'm going to be over there to get you. We're going to go shopping." And I said, "Okay." And he did that, and we went out to eat with my son, and it was nice. And then when we went in the store, I was just ... I guess, overwhelmed. I couldn't, I couldn't focus on anything. You know there was all these colors and all these choices and I 
didn't know what to look at first, and he was like "you know what, why don't you stay back here in the fitting room and I'll just bring you outfits and whatever you like, and [whatever] feels good, that's what we'll get. [R15]

Many of the individuals interviewed in this project have been denied resources in prison because of their resolution in proclaiming innocence, or in the minds of correctional officials, denying responsibility. After incarceration most states have no structure to support the transition and assume that individuals will be able to adjust, or that friends, family and the community can and will assist. As the average time served among exonerees we spoke to was over 18 years, many loved ones that might offer support have moved on with their lives, migrated to new parts of the country, or passed away. Ultimately, the reentry process for exonerees starts bleak and in many cases, becomes harder throughout the years.

\section{B. Insufficient Support}

I feel [that for exonerees it is] worse because there's no system in place for exonerees $[\ldots]$. There's nothing established by legislation or anything. There hasn't been anything in place to try to assist us, to give us financial assistance or housing assistance or education. So, I honestly feel that we're being actually prejudiced [against] by this lack of system being put in place. I think actually a person that comes out paroled is in a better position because there's a bunch of organizations out there for them. [R2]

R2's quote highlights what nearly all of the respondents shared with us - that there are few support services available to exonerees and worse, they feel abandoned by the system. After the initial excitement of release waned, it became all too clear for exonerees that they were ill-equipped to establish their new lives. The majority were released without any transitional planning and without support services in place. In the first few months after release, housing instability was common along with inadequate access to medical care, food, and financial resources. Those without family nearby to assist them found themselves with nowhere to settle, raising doubts about their futures. Some felt hopeless as they struggled to find stability. R10 commented, "I was broken, I was struggling, I had jobs here and there [...] my living situation was really bad." Echoing this feeling of desperation and lack of certainty about the future, R3 stated, "I'm 33 years old and living on the couch with zero, with ten years of no work experience and I don't really know where I'm going next."

In addition to housing, access to medical care was a major concern raised by exonerees, particularly because they experienced a range of health issues following their release, including asthma, high blood pressure, diabetes, cancer, and mental health disorders, to name a few. Several mentioned that it took months before they had medical care or that their coverage was inadequate. They found themselves having to pay for services out of pocket or not get the treatment they needed. R22 shared,

I couldn't get any resources; I couldn't get health care. I couldn't, and that was hard because I couldn't get my dental work, I couldn't get physicals. I had to pay full, 
full amounts for these things and it was, it was very difficult. The resources weren't there $[\ldots]$.

The inability to access affordable health care adds to the burden exonerees experience at a time when their physical and mental health needs are significant, and the cumulative stress they experience could very well contribute to a worsening of their conditions.

The overwhelming majority of respondents were not able to find immediate work or find jobs that provided financial stability. Those who found employment were in a better position to meet their needs. In the absence of well-paying jobs, some of the exonerees had to apply for public assistance. R2 informed us that there is no support available to exonerees beyond what is available to other citizens through government programs.

I've had to apply for public assistance. That's the only type of assistance that is available." [...] "[I]t took me about a month and a half before I actually saw anything maybe a month and a half or two. Yeah it takes a little while but I'm on Medicaid and public assistance.

Like the respondent above, R3 agreed that the only social supports available are the same supports afforded to everyone else. He indicated that he was a welfare recipient and received food stamps, but he was notified that assistance was contingent on him actively seeking employment and attending job fairs.

Having no resources upon release and having to navigate bureaucracies to apply for and access supports may feel like another form of victimization by the State. In fact, the majority of respondents seemed to take stock of what they were provided with upon their release, particularly in relation to parolees. There was widespread agreement that parolees receive an array of services and supports both through parole and through reentry organizations that is simply not available to exonerees. R13 views parolees as having several advantages over exonerees, which are reflected in the following statement:

Oh yeah. Yeah, because they [non-exonerees leaving prison] get reentry help, they get housing, they get food stamps, they get clothing. [...] I had a good time, believe me, buying my wardrobe. I did but it'd have been nice if somebody would have given me three outfits [...] I think that they have resources available to them that the rest of us don't have.

There is typically some period of transitional planning for parolees prior to release, and they often receive assistance in setting up their support system. Several other advantages to being on parole were highlighted by respondents, including the benefit of having a guide through the reentry process as well as routine monitoring. R12 stated, "it helps when you have a probation or parole officer helping point you in the directions of the grants. I had none of that [...] But it helps when you have a P.O. pushing, you know, these people." R17 also feels that that certain parole requirements, such as having to maintain employment, might help motivate parolees as well as give them access to job-related services that exonerees do not have. These advantages were in fact noted by R18, who spent 16 years on parole before he was finally exonerated. While he felt a great 
deal of anxiety over complying with the conditions of parole, he believes that having to report kept him motivated and on track. He also thinks that being on parole gave him the encouragement he needed to find and maintain gainful employment.

The respondents who were legally exonerated felt abandoned by the State and had difficulty accessing supports through non-profits. R15 was specifically told by a staff member at a reentry organization that she was ineligible for services due to her exoneration, even though her record was not expunged. Without a central structure in place to connect them to services, exonerees are "cut off" from social support and feel disconnected. Achieving their freedom is often the first step in a very long and difficult road to reintegration. The next section will document the long-term challenges that exonerees experience.

\section{The Long Road Ahead}

I think I had delusions of grandeur that it was going to be much easier than it was. I somehow thought that I'd come home and I'd find a job and things would pretty much return to normal within six months or so and boy, was I in for a big surprise. [R23]

R23's quote reflects the reality of the enduring effects of wrongful conviction. Exoneration is not a magic wand that restores life to "normal." The majority of our respondents experienced long-term hardships related to technology, financial stability, stigma, mental health, and social relationships.

\section{Technology}

To be functional in modern society individuals are expected to rapidly understand significant cultural, technological, and legal changes upon release. While prisons are not completely removed from the rest of society since some of these changes (customs, language, information about current events, etc.) make their way in regardless of how high the walls are, those we spoke with felt they were significantly behind their peers. As R3 explained two years after release, 'I'm still on an extreme lag. I'll always be 10 years behind. That's why now I'm 38 and I'm still in school. Take that 10 years back and I would have been out of school 10 years ago. I might be on my second career by now. I haven't even started yet."

In our sample, changes in technology were described as the most startling and most challenging issue to overcome right after release. Some incarcerated people are able to get access to computers and some forms of technology, but these exposures are viewed as privileges granted to individuals for a variety of reasons, including taking responsibility for criminal behavior. In the case of wrongfully convicted people, taking responsibility often means admitting to both the criminal offense and accepting state punishment. For example, R18 explained that he was always willing to participate in programs and treatments, but that his access was limited because he never accepted guilt for the crime of which he was convicted. Among the respondents, few individuals had access to computers or other technology trainings and since their sentences were so long, the world they returned to had changed considerably. 
I did not know how advanced technology had moved since I've been... 17 years is a long time. That's a teenage life. So, you come home in 17 years, and like my 3 and 4-year-old nieces, they can operate my phone and computers like professionals. I'll sit here stuck and they [say] "give it me." [R9]

Most prison re-entry scholars connect lapses in technology-related skills to employment barriers (e.g., Ogbonnaya-Ogburu et al., 2019), and, to a degree, those we spoke with corroborate these findings. However, to those we interviewed here, technology was more vital than employment and framed almost all aspects of social life. R3, for example, was frustrated that he couldn't access basic communication resources like email and social media: "It took weeks and weeks just to build up a familiarity with the Internet or getting a Facebook account, getting a Gmail account and understanding the difference between logging into Gmail and logging into Facebook which would seem like a very simple thing when it comes slowly but all at once it can be a lot." R21 was similarly frustrated. It seemed to him that people no longer even communicated the same way. He still tries to call people, but is irritated that no one picks up the phone. He's started to adapt but he feels it is not just learning how to use a new device, human interaction has changed. Others shared this observation that the nature of human interaction evolved in their absence. R6 recalled his unfamiliarity with the norms and conventions of social media:

I took to social media. Like Facebook, for example...That was not good for me because what happened, I started friending everybody and what my friends started saying to me was [...] you have to be careful about that and who you're friending and all these kinds of things. Cause eventually these people can tend to...get into your business, you wanna know who's who and all those kinds of things. So, [...] that was a learning experience $[\ldots]$.

\section{Financial Stability}

As noted above, the majority of respondents were released with little to no support from the State and had to rely either on what they accumulated in personal savings or on support from family members. Compensation is not guaranteed in all states, and even when it is, the rewards are not automatic. Exactly half of the exonerees we spoke with received compensation by the state. ${ }^{5}$ For some, funds were received in a timely matter (within the first year), others had to wait decades to be compensated. The amount of compensation ranged from $\$ 10,000$ to several million. Among the twelve individuals who did not receive payment from the state, three have claims that are pending and the remainder either live in states without compensation statues or they are ineligible (e.g., plead guilty, falsely confessed, case still opened, etc.). To illustrate this challenge, R8 expressed the following:

Some of it is [...] trying to transition back into society which is difficult for some people, and some of it is also trying to get compensation. You know, a lot of guys have been going...decades, and we have to file suits which is ridiculous [...] to get some type of compensation, and then they fight us on that. Like, this whole situation is ridiculous. Because if somebody, you know, like if you take somebody's life for 20 -something years in prison. Then come home most of the time, by the time we

\footnotetext{
${ }^{5}$ This includes exonerees who were compensated either through existing state statutes or state court of claims. It does not include individuals who received funds from civil lawsuits or a private bill.
} 
come home, we'[re] older, we'[re] not in the best of health, you know we, we don't get no type of health benefits, we don't get no jobs. We don't have anything.

It is clear that $\mathrm{R} 8$ feels exonerees do not have adequate resources to navigate the long-term challenges they face, such as unemployment and poor health. Other respondents felt that the compensation they received was inadequate. R9 waited 15 years to be compensated, and was compensated only after an automatic compensation law was passed. Even then, he did not feel that a monetary value could be placed on all that he lost. R19 expressed a concern that compensation on its own is not enough unless additional resources are also provided, such as counseling and financial advising. In the absence of these additional resources, settlements provided might not be enough to sustain exonerees as they navigate reentry challenges.

Not all respondents were legally exonerated at the time of their release. Some were released on recognizance after newly discovered evidence raised questions about their convictions. Others were released on parole before their convictions were overturned. These respondents were not entitled to compensation until they were legally exonerated, which was months to years later in most cases.

In these circumstances, some respondents waited several years beyond that for their records to be expunged, complicating the process of finding employment and further undermining their financial stability. As R23 stated, "nobody wants to hire a person who has been in prison for 14 years for murder." R14 agreed that with the conviction still on his record, no one would give him the benefit of the doubt. He explained, "I was a liability. Nobody's going to take a chance. At the time I had not been exonerated so, you know, it's hearsay, you know, nobody would, nobody would trust me."

Those who are legally exonerated at the time of release do not always fare better than those who are not. Several respondents faced skepticism and felt they had to answer for their convictions even after they were cleared of their crimes. In their view, many assumed they were still guilty or somehow involved in the crime and were let off on a technicality, which made it difficult to find well-paying job opportunities. R4 reported, "cause even though we were exonerated it was still difficult. Like there still were no jobs because people were still saying we were guilty." He further commented that potential employers assumed, "They got exonerated, but they got exonerated on a technicality. They must have did something. And that's what people couldn't let go."

Even when employers are sympathetic, they are often reluctant to offer jobs to individuals who spent time behind bars. According to R20,

People are sympathetic, but because of the way of the world today and the things that are happening, when they go to hire you [...] people look at you, they look at your mentality, what you been through, the type of person that you might be, because you got to be working with other individuals.

R20 perceives that employers are concerned about the effects of institutionalization despite his innocence. There is also a common viewpoint among respondents that even if their records have been expunged; their names will turn up in an Internet search causing them to lose job 
opportunities because employers view them as a risk. R20 faced years of difficulty in securing stable employment, even though he was pardoned by the Governor. He explained:

[...] everywhere I turned my conviction kept coming up for some particular reason. It would show up when I go for employment positions and stuff, even though I had a full unconditional pardon from the governor, even though I had an expungement order signed by administrative judges that the records were no longer acceptable and all. They will still come up and then I would have to answer for them and what person when you telling her that you'd been wrongfully imprisoned for something [for 10 years] and you've only been home 2 years. They don't know anything about you. They had no idea what type of person you are, with the kind of involvement that you been in, the pain that you've been subjected to, your kind of mentality. You know, so it became a lot harder during that time.

Decades later, R20 is still being denied job opportunities due to his past. He expressed disbelief that he always finds himself having to explain a wrongful conviction from more than 30 years ago.

There are other barriers to finding employment in addition to stigma. Some respondents feel they have limited opportunities because they lag behind others in terms of marketable skills. R1 told us he had trouble finding gainful employment not because of his guilt but because of his lack of experience compared to other job seekers.

R8 explained that individuals who are incarcerated are unable to acquire skills that keep pace with societal and technological change:

Whatever job training, or skills, we may have learned inside the prison, is you know, out of date. Because while we're working with these computers out here, what they're working with in [prison], business 2003 type, you know, computers. They have no Internet, so they're working with stuff that's out of touch with what society is dealing with. So, when we come out here, we just seem lost, like really don't understand what's going, and unfortunately, they didn't do anything to try to assist and fix the transition.

This is yet another example of how technology presents challenges to successful reintegration. While incarcerated, individuals typically do not have access to the most recent technological developments, creating deficits in their qualifications. For those who are incarcerated for many years, disruptions in work history serve as an additional barrier to employment. R11 stated the following:

I had no idea what I was going to do... didn't know how to do anything, and no one would hire me. I went in when I was 27, I came out when I was 45. Nobody's hiring a 45-yearold woman with no work experience, who was in prison, but she didn't do it right?

While limited skills and work histories are a barrier faced by other individuals who have been incarcerated and are not unique to exonerees, it is particularly cruel that they should have to 
experience these challenges given the injustice they suffered. In the face of these obstacles in securing employment, some of the participants felt they could never fully rebuild their lives.

\section{Stigma in the Community}

While they clearly experienced discrimination in the job market, many exonerees felt stigmatized in the broader community when they returned home. When asked if people doubted her innocence, R11 replied,

[They] still are. That follows, that is the shadow. That Peter Pan shadow that follows you forever. Wherever you go, you can't cut it off and put it in a drawer. It, it, that's always going to be with you. There's always going to be somebody who says, 'Oh, yeah, I was a technicality,' or you know whatever and you just have to accept that. There will be people, that's just part of the lasting effects of wrongful conviction.

This is similar to what R4 described earlier about his experience in the job market - that even though they have been exonerated, some will assume they got off on a technicality. Several respondents described a similar feeling within the community. They perceived there to be an assumption that they were still somehow involved in the crime. R7 recalled what it was like when she returned home and encountered those who doubted her innocence:

I mean that was a lot of people [that doubted me] but I didn't come in contact with them really until I felt the stigma of that community when I got out. I mean as far as them not wanting their children being around me, or people talking about me or calling me child killer, and that kind of thing like that. Some people were like, 'I slipped through the cracks of the system.' You know, they were on the good side, of the DA.

Some respondents had to contend with the police and/or prosecutor continuing to assert their guilt following their release, which contributed further to doubts of their innocence among the public. R23 indicated,

Yeah, well, the official statement from the district attorney's office and the chief of police was, 'I'm guilty.' They know they had the guilty person, there was evidence that my attorney wouldn't let be brought out at trial and I got off on a technicality, but people, good people of the city could rest assured, they were going to take me back to trial and send me back to prison.

In communicating to the public that the respondent was actually guilty, R23 was afraid that the State would set him up to be re-convicted. In fact, several respondents expressed a fear of being victimized by the State again. They were concerned about being framed by the police for another crime because it happened so easily the first time. Some even feared retaliation by the police because their exoneration made the department look bad.

Stigma was experienced in other ways as well. Regardless of whether or not people believed in their innocence, the respondents believed that others in the community viewed them 
with caution because they thought the prison damaged or changed them in negative ways. R9 explained it as such:

Even being exonerated, just the concept of being in prison and when you go meet people, they'll still see and look at you like, as if you are a convict cause you went through the experience of it. There's no way going through the experience not adapting to that environment, which I had to survive. Um, that aspect of the stigma follows me everywhere.

It is undoubtedly difficult to heal in a community where one feels unwelcome or mistrusted. Our interviews revealed a wide range of emotions experienced by exonerees upon their return and they may struggle to cope with these emotions for many years.

\section{Mental health}

Respondents experienced a range of mental and emotional health problems, interfering with their ability to move forward. These included trust issues, difficulty with emotional expression, depression, PTSD, and even guilt. Trust was a theme that emerged in relation to reestablishing social ties. Establishing trust in personal relationships was difficult for some exonerees, in part due to the injustice they experienced and in part due to being in prison. Respondents noted that after years of institutionalization, it is difficult to let your guard down after returning to the community. R18 explained that among the biggest challenges of reentry was:

[...] abandoning the convict mentality and getting back into normal life, that not, not everybody was a goon that was out to get you. That, there, there are good folks out here and that was the perception, [...] everybody had it in for you before, every, everybody was a possible enemy.

R15 similarly questions others' motives and stated simply that he doesn't trust people anymore. He finds himself wondering what others are seeking to get out of a relationship with him.

Difficulties with emotional expression further complicate reintegration experiences. Emotional turmoil in the years following their incarceration was common among respondents, even as they experienced joy and relief in finally being free. For some, expressing their emotions was difficult because they were desensitized through their institutionalization. R16 explained,

Being [in prison] and being raised by wolves, you know, I mean staff speaking of, and you know the mentality and the attitude that they had had towards me in a way they treated me and just my environment. The environment alone it desensitized me, it desensitized me, so it's hard for me to do naturally what one's supposed to do like shed tears... at events where one should shed tears, you know? For me, this is that much difficult for me to be able to express my emotions and I attribute that to where I came from. Trust me.

R16's statement reflects the struggle exonerees may have in releasing their emotions after years of having to suppress them. R24 detailed how the suppression of emotion while incarcerated was a barrier to his healthy emotional functioning after his release: 
A wrongful conviction has you physically locked up, but emotionally and mentally it's like, [...] you have to be strong [...] I couldn't show any emotion, I couldn't. I had to be strong. I was still trying to come home and it's like, you have to put [on] this front because you have to survive in there and you kind of just go with the flow of everything and so emotionally, I feel like I never learned how to deal with my emotions. So, I kind of like [...] bottled it up and now it's hard for me to do that, you know, I've gone to a couple of counseling sessions. [...] I fought for so many years. We're talking about 20-something years and now what do I do? I fought for so long. I don't even know what to do anymore. I don't know what kind of future I want [...] because you can never plan those things because you never know what might happen and [...] you know, all these emotions that I [...] I wasn't in touch with all these years, I'm trying to get in touch with now and I'm a mess. You know, emotionally, I just react wrong or I just, I don't know how to express myself. I get frustrated and it's like, you know, it affects my family, it affects my wife, you know, it's just, it's horrible, but I know I'm the one that needs the help.

There is a range of emotional experiences described in the above account. The respondent struggles to respond to situations in socially appropriate ways, which has complicated his intimate relationships, but the emotions he grapples with have also depressed his outlook for the future. He seems to have developed a generalized anxiety about life.

Several respondents experienced depression and PTSD following their return home. Even routine events in their daily lives can trigger their trauma. R12 explained:

But mentally, you know, we're not really mentally stable sometimes, you know, cause you hit the bout of, you know, depression, or you'll hit a bout of PTSD. You'll hit these moments of rough life where most people don't have, you know, and we hit $[\ldots]$ certain triggers $[\ldots]$ where $[\ldots]$ for me, you know, I watch certain shows or [hear] certain sentences or, you know, when you're having a conversation or, again like I said, when you remember certain things, you know?

The respondent said that hearing certain words in everyday conversation, or simply viewing television shows, can trigger memories of traumatic events. These situations are almost unavoidable. Others mentioned that talking about their experiences of wrongful conviction triggered their pain, even if they felt it was important and ultimately therapeutic to do so. In describing the impact of talking about her experience, R15 stated:

It's always, it's always very emotional. [...] I lost [time with] my child, and that, it's never going away. It's never going to heal. It's never going to be okay. I'm never going to be okay with that. I'm always going to be sad. I'm always, it's always going to take a toll. It's going to wear me down, but I know that many other women exonerees can't talk about their experience. They are too hurt, they're too broken, they're too scarred. So, no matter how much it, it wears me out, I'm gonna keep doing it because I want people to know that it's not just me. 
Although she feels a sense of responsibility in sharing her story, the respondent is reminded of all that she lost in the process. R16 similarly explained that sharing his story opens up wounds that have never fully healed, "at first, initially, you know, it used to like compound my injury [...] it would just rehash...wounds that I don't think will ever close...".

In addition to experiencing emotional and psychological turmoil, several respondents expressed feelings of guilt for various reasons, including surviving long enough to be exonerated when their co-defendants did not, implicating others during forced confessions, and leaving friends in prison behind. R6, for example, described conflicted emotions over his exoneration because his co-defendant died in prison. He explained:

Walking out the courtroom, after I was exonerated...it was really kind of mixed. I had mixed emotions [...] Leaving the court room of course I was very, very happy and excited to be out for one and to see my family that supported me and to see [his] family there too. But, at the same time, I was very sad too because I know that I was walking out of the courtroom, you know, without this man, you know, and, unfortunately for him, he passed away in prison [...].

The respondents also reported feeling guilty over leaving their friends in prison behind. R12 told us, "I mean, an honest truth, it hurts sometimes because I think about my friends in there. So, it hurts that I left them." The guilt described by respondents was in part due to leaving friends behind but also leaving behind others who might be innocent. In discussing her advocacy efforts, R15 informed us that she fights for new legislation for the ones they left behind and to, "make things better and right for them."

R12 also grappled with feelings of guilt over implicating his friends in the crime, and it continued to eat away at him and impede recovery even though they eventually forgave him.

You know, there's a lot of things that I still haven't dealt with myself with mental problems as it is. But I still haven't dealt with some of the things, you know, I still live with the guilt cause again, like I told you, I implicated other people in this crime that had nothing to do with it. But these people were my friends... We've all worked out the, you know, the hatred and the feelings and we've moved past that, but for me, I haven't. I still know what I did was wrong, even though I didn't have a choice. But I know it's wrong, and it eats at me daily, you know, So there are a lot of, you know, it's just mental problems that we, I shouldn't say we, but for me, it's just trying to work through and live with every day.

The participants overwhelmingly said they do not feel a sense of closure. Even among those who are fully exonerated, have expunged records, and received compensation, there is widespread agreement that they will never fully recover. These reparations are too little and too late given all they have lost. 


\section{Social Relationships}

Social relationships changed drastically for the respondents while they were incarcerated, which became all too clear when they returned home. In some cases, their severed bonds were beyond repair. Some experienced the dissolution of their romantic partnerships as a result of their convictions and imprisonment. Many experienced the loss of one or both of their parents while incarcerated and they were hit hard with that reality upon their return home. The emotional consequences of their wrongful conviction and imprisonment were exacerbated by grief over the loss of their parents. Others lost valuable time with their children and struggled to repair the emotional connection between them, especially because most of their children were very young at the time of their conviction. R11 experienced several types of loss as a result of her incarceration. She explained:

I'm also trying to reconnect with my children, you know, people, a lot of people didn't have the good fortune to have had children before they went in and those who did, you know, not all have the good fortune of being able to stay connected with them. And so, when my parents died that [was] sort of the end of my connection to my children. [...] I saw them four times a year during school holidays. So, who am I, you know? So the shorter answer is that you become estranged, yeah, so that's one of the difficulties is trying to reconnect with your children or whatever family you might have, And on their end of it, they feel often guilty for not having perhaps believed you are not being supportive enough and so that remains between you, so it's hard.

This respondent lost her parents and ultimately lost touch with her children, making it difficult for her to reconnect with them, but her quote also reflects an awkwardness that can set in when family members feel they let down their loved ones. R1 described a similar phenomenon:

More recently as I've interacted a little bit, albeit sporadically, once in a blue moon type thing with members of my extended family, there is awkwardness on their part they'll bring up, you know, they're sorry they weren't there for me, that kind of thing, sorry they didn't help me they didn't know. That kind of thing.

An awkwardness can also result from the fact that time has advanced in the exonerees' absence and their loved ones have moved on with their lives. R10 noted, "after a while, people get so used to you not being around that they like kind of forget you, so." In fact, several participants mentioned that their families moved away from their hometowns and they did not have any family to return home to, making the transition all the more difficult. These individuals seemed to face the greatest challenges in finding stable housing and navigating the social world.

\section{Discussion and Policy Considerations}

Over the past two decades, researchers have repeatedly reported that wrongfully convicted people face continuing hardships upon reentry. What is shocking is that despite an increase in the number of innocence organizations, growing bi-partisan support for criminal justice reform, and increased attention on wrongful conviction cases, little has changed for exonerees. We find here 
that even individuals that have received compensation and/or been free for decades continue to face significant challenges. For some the barriers have changed but largely, they still exist.

Since exonerees are not considered to be under the care of the criminal justice system once convictions are overturned, they do not often have access to the same reentry services offered to other citizens recently released from prison. Thus, exonerees can rarely take advantage of prerelease counseling, job training, substance abuse treatment, and housing assistance, and have no point person, as parolees commonly do. This lack of access to services often compounds the stress of post-incarceration adjustment among exonerees. As R16 explains:

In comparison to a parolee, an exoneree, has no chance whatsoever with succeeding. [...] When a parolee come[s] home [...] and you['re] still a ward of the state, you have a laundry list of assistance... [I]t would have been more befitting for me to come home, like, on some type of parole because I would have been able to have the amenities of six months free housing assistance. I would have had the mental treatment or help... help and support and all other things that, as an exoneree, you get nothing but an apology, whether it's sincere or not. [...] that's it.

At a minimum, exonerees should have access to the support offered to parolees, as we found exonerees who did have access to them valued them. We should, however, go beyond minimal one-size-fits-all services. Assistance should be customized to individual needs, which would require empowering exoneree voices so they have some ownership over the process. In our study, exonerees cited multiple complex challenges related to technology, financial stability, social adjustment, mental health, and negative perceptions in the community that shifted over time. The exoneree population is small enough that customizable support is attainable with political will.

A major focus should be to build exoneree skills needed to be successful in society. Current technological training should be a priority as many exonerees report difficulties acclimating to society after sometimes lengthy imprisonment. Following release, additional workshops and mentorships should be offered to assist with both job-readiness and social skills.

As others have also noted (see Westervelt \& Cook, 2012) exonerees want recognition of the harm done to them - harm that is caused not only by the individuals working for criminal justice organizations, but the institutions themselves. Exonerees express the need for both compensation and public apology. A system should be put in place to accomplish both of those objectives. Not only would this help wrongfully convicted individuals heal, it may alleviate community stigma. R11 explained this dual need:

An apology is validation. [It] validates you as a human being. And I think that's helpful. [...] Compensation also validates us [as] human beings and gives you some degree of satisfaction, you know? That at least they recognized me in that way.

Without assistance or guidance throughout the reentry process, exonerees' only means of restoration is often financial compensation (Martin, 2006). In places that do provide compensation, the calculation can be impersonal and removed from the lived experiences of exonerees. R9 describes this state calculation: 
I did get compensation for, yearly for six years. But the thing with compensation is, they give you what they think you should have. And nothing else. The time. They start calculating your years, hours, time. I don't know how you can calculate somebody's life, that you took, but that's how they do it. And they issue it out to you, the way they think you should have it.

Post-release needs extend beyond monetary fixes. Individuals also desire access to, and resources for, mental health services. These services should be provided immediately after release and should continue for as long as exonerees feel they need it. Researchers have also found that speaking about their experience helps some exonerees build confidence through acknowledgment and affirmation (Konvisser, 2015). As such, funding should be directed to organizations like Healing Justice, the Sunny Center, and others that are providing safe spaces for all those who are harmed by wrongful convictions.

The federal government currently provides few resources for exonerees. Several states recognize exoneree needs but support is piecemeal and inadequate. More federal and state funding should be allocated for exonerees and other victims of miscarriages of justice and these resources should not be wholly run by state agencies. Non-governmental organizations, which are increasingly directed or staffed by exonerees, should be financially supported in their crucial work.

It is evident that exonerees face significant, multi-faceted, barriers after release from prison. A holistic approach that can address these needs is necessary. We, as a society, can no longer turn our backs on those we have harmed so greatly. While some argue that we have made great strides in addressing the factors that contribute to wrongful convictions, there is limited public policy reform addressing life after exoneration.

\section{A. Limitations and Future Research}

As discussed in the introduction, the universe of those wrongfully convicted is simply unknowable and likely well above the official rates reported by the Innocence Project and National Registry of Exonerations. The findings presented here may illuminate some of the struggles faced by exonerees after release but are not necessarily illustrative of the needs and obstacles faced by the general population of exonerees.

Further, in this study we relied on snowball sampling from individuals connected to innocence networks, therefore, our sample might be comprised of individuals that are more connected and thus, more likely to have access to resources upon reentry. Prior research has also shown that recruitment may be particularly challenging for individuals with a significant trauma history (e.g. Rose et. al., 1999). While many exonerees believe in the importance of speaking out in an effort to educate and raise awareness of systemic injustices, others feel that their involvement can be re-traumatizing and trigger posttraumatic stress disorder (PTSD) symptoms (Weigand, 2008).

In our analysis we did not focus directly on comparing demographic characteristics of exonerees to determine how these characteristics may have shaped the reentry experience. In future interviews, and the next phase of this project, we will add new questions and expand our analysis 
to incorporate issues related to race, class, gender, and other forms of identity. We acknowledge that the current work only reveals anecdotal differences and a more systematic investigation is warranted. Additionally, in this paper we focus only on challenges after release from prison, and omit the many examples of positive reentry we heard throughout the interviews. In future publications we will highlight these narratives to expand on ways exonerated people have adapted to challenges and found success despite barriers. Next, it is still unclear whether, and in what ways, exonerees experience reentry different than other formerly incarcerated individuals. Future research should compare these groups to differentiate their lived experiences after prison. Lastly, in subsequent works we hope to expand in more theoretical directions. For example, Westervelt and Cook $(2008 ; 2012)$ found in their interviews a form of survivor's guilt where exonerees feel remorseful for living while others remain incarcerated or died. This guilt sometimes manifests into hyper-arousal, intrusive thoughts, feelings of hopelessness and apathy. After prison, exonerees sometimes have difficulty envisioning the future, connecting to others emotionally, and struggle with feelings of fear, worthlessness, helplessness, isolation, and rejection. In our interviews, respondents also described various examples of guilt, such as regret that they were able to leave prison while friends or others believed to also be wrongfully imprisoned remained incarcerated. Many exonerees in our sample became involved in the innocence movement to provide a way to give back and fight for others who have experienced injustice. We hope to expand these ideas in future works and differentiate types of guilt and outline how exonerees cope with these feelings.

\section{Conclusion}

The conviction and subsequent incarceration of an innocent person is the ultimate miscarriage of justice. Although wrongful convictions may just be a small proportion of all cases that pass through the system, individual lives are disrupted, communities are torn apart and public confidence is undermined. In addition to these detrimental effects there is a public safety concern; when an innocent person is in prison it often means that a guilty person is free (Norris, et.al, 2020).

While it is likely that many wrongfully convicted and incarcerated people remain in detention, some have been released and recognized by the state as innocent through the exoneration process. Nevertheless, these individuals face substantial challenges re-entering society. Exonerees are often stigmatized, isolated, denied access to government benefits, suffer additional law enforcement scrutiny, and face significant healthcare barriers.

In this paper we have highlighted many of these obstacles and suggested some broad and concrete ways to begin to address them. The experiences and struggles faced by this unique group of individuals highlights the urgent need to provide support to individuals who have been victimized by the very system that is supposed to protect their fundamental rights. It is our obligation as a society to provide assistance to help exonerees upon release. 


\section{References}

Alexander-Block, B., Miller, M. A., Zeringue, M. M., \& Rubens, S. L. (2020). Mental Health Characteristics of Exonerees: A Preliminary Exploration. Psychology, Crime and Law, DOI: 10.1080/1068316X.2020.1733571.

Armbrust, S. (2004). When Money Isn't Enough: The Case for Holistic Compensation of The Wrongfully Convicted. The American Criminal Law Review, 41, 157-182.

Bell J. G., Clow K. A., \& Ricciardelli R (2008). Causes of Wrongful Conviction: Looking at Student Knowledge. Journal of Criminal Justice Education, 19, 75-96.

Berg, M., Huebner, B. M. (2011). Reentry and The Ties That Bind: An Examination of Social Ties, Employment, And Recidivism. Justice Quarterly, 28, 382-410.

Blandisi, I. M., Clow, K. A., \& Ricciardelli, R. (2015). Public Perceptions of the Stigmatization of Wrongly Convicted Individuals: Findings from Semi-Structured Interviews. The Qualitative Report, 20(11), 1881-1904.

Branham, L.S. (1992). The Use of Incarceration in the United States: A Look at the Present and the Future. Chicago, Ill: American Bar Association, Criminal Justice Section.

Bronson J, Berzofsky M. (2017) Indicators of Mental Health Problems Reported by Prisoners and Jail Inmates, 2011-2012, 1-17. Washington, DC: US Department of Justice.

Campbell, K. \& Denov, M., (Guest Editors) (2004) "Wrongful Conviction: Perspectives, Experiences and Implications for Justice". The Canadian Journal of Criminology and Criminal Justice, 46, 2.

Chamberlain, A., Nyamu S., Aminawung J., Wang, E.A., Shavit S., \& Fox A.D. (2019) Illicit Substance Use After Release from Prison Among Formerly Incarcerated Primary Care Patients: A Cross-Sectional Study. Addiction Science \& Clinical Practice 14(1).

Chandler, R.K., Fletcher, B.W. \& Volkow, N.D. (2009). Treating Drug Abuse and Addiction in the Criminal Justice System: Improving Public Health and Safety. The Journal of the American Medical Association, 301(2), 183-190.

Charmaz, K. (1990). 'Discovering' Chronic Illness: Using Grounded Theory. Social Science and Medicine, 30, 1161-1172.

Chunias, J. L., \& Aufgang, Y. D. (2008). Beyond Monetary Compensation: The Need for Comprehensive Services for The Wrongfully Convicted. Boston College Third World Law Journal, 28, 105-128.

Clemmer, D. (1940). The Prison Community. Boston: The Christopher Publishing House.

Clow, K.A., \& Leach, A. (2009). After Innocence: Perceptions of The Wrongfully Convicted. Paper presented at the 2009 American Psychology-Law Society Conference, Antonio, Texas.

Clow, K. A., \& Leach, A.-M. (2015). After Innocence: Perceptions of Individuals Who Have Been Wrongfully Convicted. Legal and Criminological Psychology, 20, 147-164.

Cook, K. J., Westervelt, S. D., \& Maruna, S. (2014). The problem of parolees, exonerees, and prisoner reentry. In Examining Wrongful Convictions: Stepping Back, Moving Forward (pp. 237-250). Durham, NC: Carolina Academic Press. 
Dijker, A.J., Koomen W. (2003). Extending Weiner's Attribution-Emotion Model of Stigmatization of Ill Persons. Basic and Applied Social Psychology, 25, 51-68.

Dworkin, S. L. (2012). Sample Size Policy for Qualitative Studies Using In-Depth Interviews. Arch Sex Behav 41, 1319 - 1320. Retrieved from https://doi.org/10.1007/s10508-0120016-6.

Garrett, B.L. \& Neufeld, P.J. (2009). Invalid Forensic Science Testimony and Wrongful Convictions. Virginia Law Review, 95, 1-97.

Geertz, C. (1994). Thick Description: Toward an Interpretive Theory of Culture. In M. Martin \& L. McIntyre (Eds.), Readings in The Philosophy of Social Science (pp. 213-231). Cambridge: MIT Press.

Goffman, E. (1961). Asylums: Essays on the Social Situation of Mental Patients and Other Inmates. New York: Doubleday Anchor.

Gross, S.R. \& O'Brien, B. (2008). Frequency and predictors of false conviction: why we know so little, and new data on capital cases. Journal of Empirical Legal Studies, 5(4), 927-962.

Gross, S.R., \& Shaffer, M. (2012). Exonerations in the United States, 1989-2012. National Registry of Exonerations. Retrieved from http://www.umich.edu/special/exoneration/Documents/exonerations_us_1989_2012_full report.pdf.

Grounds, A. \& Jamieson, R. (2003). No Sense of an Ending: Research the Experience of Imprisonment of Imprisonment and Release among Republican Ex-Prisoners. Theoretical Criminology, 7, 347-62.

Grounds, A. (2004) Psychological Consequences of Wrongful Conviction and Imprisonment. The Canadian Journal of Criminology and Criminal Justice, 165.

Grounds, A. (2005). Understanding the Effects of Wrongful Imprisonment. Crime and Justice 32, $1-58$.

Haney, C. (2002) The Psychological Impact of Incarceration: Implications for Post-Prison Adjustment. In: Paper presented at the 'From prison to home' conference, working paper prepared for the 'From Prison to Home' Conference (January 30-31, 2002).

Hirschfield, P.J., \& Piquero, A.R. (2010). Normalization and legitimation: Modeling stigmatizing attitudes toward ex-offenders. Criminology, 48, 27-55.

Howard, S. (2018). Exonerees in Black and White: The Influence of Race on Perceptions of Those Who Falsely Confessed to a Crime. Psychology, Crime \& Law, 25, 1-16.

The Innocence Project (2020). Exonerate the Innocence. Retrieved from https://www.innocenceproject.org/exonerate/ on June 20, 2020.

James, D. J., \& Glaze, E. (2006). Mental health problems of prison and jail inmates. http://bjs.ojp/usdoj.gov/content/pub/pdf/mhppji.pdf.

Kaeble, D. and Glaze, N. (2016). Correctional Populations in the United States, 2015. Washington, DC: Bureau of Justice Statistics; Corrections: Key Facts at a Glance. Washington, DC: Bureau of Justice Statistics. 
Kassin, S. M. (1997). The Psychology of Confession Evidence. American Psychologist, 52, 221233.

Kassin, S. M. (2002). False Confessions and The Jogger Case. The New York Times, November 1,2002, A-31.

Keene, D. E., Smoyer, A. B. \& Blankenship, K. M. (2018). Stigma, Housing and Identity.

Konvisser, Z. D. (2015). "What Happened to Me Can Happen to Anybody"-Women Exonerees Speak Out. Texas A\&M Law Review, 3, 303-366.

Kukucka, S., Applegarth, H.K. \& Mello, A.L. (2019). Do Exonerees Face Employment Discrimination Similar to Actual Offenders? Legal and Criminological Psychology, DOI:10.1111/lcrp.12159.

Leo, R. (2005). Rethinking the Study of Miscarriages of Justice: Learning from Social Science. Journal of Contemporary Criminal Justice, 21, 201-223.

Looney, A. \& Turner, N. (2017). Work and Opportunity Before and After Incarceration. Economic Studies at Brookings Technical Report.

Lopez, A. (2002). \$10 And A Denim Jacket? A Model Statute for Compensating the Wrongly Convicted. Georgia Law Review, 36, 665-722.

Mallik-Kane, K., Visher C. A. (2008). Health and Prisoner Reentry: How Physical, Mental, and Substance Abuse Conditions Shape the Process of Reintegration. Washington: The Urban Institute.

Mandery, E., Shlosberg, A., West, V. \& Callaghan, B. (2013). Compensation Statutes and PostExoneration Offending. Journal of Criminal Law \& Criminology, 103, 2, 553-583.

Martin, K.D. (2006). A Model State Policy for The Treatment of The Wrongfully Convicted: A Study Conducted for The Life After Exoneration Program. Master's thesis, University of California at Berkeley.

Maruschak, L.M., Berzofsky, M, \& Unangst, J. (2015). Medical Problems of State and Federal Prisoners and Jail Inmates, 2011-12. Washington, D.C: Bureau of Justice Statistics.

Middlemass, K.M. \& Smiley, C.J. (eds). (2020). Prisoner Reentry in the 21st Century: Critical Perspectives of Returning Home. New York, NY: Routledge.

Menard, S. \& Pollock, W. (2014). Self-Reports of Being Falsely Accused of Criminal Behavior. Deviant Behavior 35, 378-93.

Moore, K. E., Milam, K. C., Folk, J. B., \& Tangney, J. P. (2018). Self-Stigma Among Criminal Offenders: Risk and Protective Factors. Stigma and Health, 3(3), 241-252.

National Registry of Exonerations (2020). Retrieved from http://www.law.umich.edu/special/exoneration/Pages/detaillist.aspx on June 20, 2020.

Norris, R.J., Weintraub, J.N., Acker, J.R., Redlich, A.D. \& Bonventre, C.L. (2020). The Criminal Costs of Wrongful Convictions Can We Reduce Crime by Protecting the Innocent? Criminology \& Public Policy, DOI: 10.1111/1745-9133.12463.

Ogbonnaya-Ogburu, I. F., Toyama, K., \& Dillahunt, T. R. (2019). Towards an Effective Digital Literacy Intervention to Assist Returning Citizens with Job Search. In Proceedings of the 
2019 CHI Conference on Human Factors in Computing Systems (pp. 1-12). https://dl.acm.org/doi/pdf/10.1145/3290605.3300315.

Pager, D. (2003). The Mark of a Criminal Record. American Journal of Sociology, 108(5). 937975.

Petersilia, J. (2003). When Prisoners Come Home: Parole and Prisoner Reentry. New York: Oxford University Press.

Rade, C. B., Desmarais, S. L., \& Mitchell, R. E. (2016). A Meta-Analysis of Public Attitudes Toward Ex-Offenders. Criminal Justice and Behavior, 43, 1260-1280.

Reingle Gonzalez, J.M. \& Connell, N.M. (2014) Mental Health of Prisoners: Identifying Barriers to Mental Health Treatment and Medication Continuity, American Journal of Public Health, 104 (12), 2328-2333.

Rose, S., Brewin, C. R., Andrews, B., \& Kirk, M. (1999). A Randomized Controlled Trial of Individual Psychological Debriefing for Victims of Violent Crime. Psychological Medicine, 29, 793-799.

Rubin, H. J., \& Rubin, I. S. (2005). Qualitative Interviewing: The Art of Hearing Data (2nd ed.). Thousand Oaks, CA: Sage.

Scheck, B., Neufeld, P.\& Dwyer, J. (2000). Actual Innocence and Other Dispatches from the Wrongly Convicted. New York: Doubleday.

Scott, L. (2010). "It Never, Ever Ends": The Psychological Impact of Wrongful Conviction " American University Criminal Law Brief 5(2), 10-22.

Shlosberg, A., Mandery, E., \& West, V (2012) The Expungement Myth. Albany Law Review. 75 (3), 1229-1241.

Simon, R.I. (1993). The Psychological and Legal Aftermath of False Arrest and Imprisonment. Bulletin of the American Academy of Psychiatry \& the Law 21(4), 523-8.

Sykes, G. M. 1958. The Society of Captives. Princeton, NJ: Princeton University Press.

The Innocence Project (2020). Retrieved from www.innocenceproject.org.

Thompson, A.M. \& Levett, L.M (2010). Exonoree Stigma: An Investigation of Attitudes Toward Guilty and Wrongfully Convicted Persons. Paper presented at the 2010 American Psychology-Law Society Conference, Miami, Florida.

Thompson, A. M., Molina, O. R., \& Levett, L. M. (2012). After Exoneration: An Investigation of Stigma and Wrongfully Convicted Persons. Albany Law Review, 75, 1373-1413.

Visher, C., Bebus, S., \& Yahner, J. (2008). Employment After Prison: A Longitudinal Study of Releases in Three States. Washington, DC: The Urban Institute.

Walmsley, R. (2016). World Prison Brief. London: Institute for Criminal Policy Research. Available online: http://www.prisonstudies.org/world-prison-brief.

Weisman, R. (2004). Showing Remorse: Reflections on The Gap Between Expression and Attribution in Cases of Wrongful Conviction. Canadian Journal of Criminology and Criminal Justice, 46, 121-138. 
Wells, G.L., Small, M., Penrod, S.D., Malpass, R.S., Fulero, S.M. \& Brimacombe, C.A.E. (1998). Eyewitness Identification Procedures: Recommendations for Lineups and Photospreads, Law and Human Behavior 22, 6, 603-647.

Westervelt, S.D, \& Cook, K.J (2008). Coping with Innocence After Death Row. Contexts, 7(4), $32-37$.

Westervelt, S.D. \& Cook K.J. (2010). Framing Innocents: The Wrongly Convicted as Victims of State Harm. Crime, Law, and Social Change 53(3), 259-275.

Westervelt, S.D. \& Cook, K.J. (2012). Life After Death Row: Exonerees' Search for Community and Identity. New Brunswick, New Jersey: Rutgers University Press.

Wildeman, J., Costelloe, M., \& Schehr, R. (2011). Experiencing Wrongful and Unlawful Conviction. Journal of Offender Rehabilitation, 50, 411-432.

Wilper, A.P., Woolhandler, S., Boyd, J.W, Lasser K.E., McCormick, D., Bor, D.H \& Himmelstein, D.U. (2009) The Health and Health Care of US Prisoners: Results of A Nationwide Survey. American Journal of Public Health, 99, 666-672.

Zamble, E. \& Porporino, F.J. (1988). Coping, Imprisonment, and Rehabilitation: Some Data and Their Implications." Criminal Justice and Behavior 71, 53-70. 